\title{
3-methylglutaconic aciduria type 4
}

INSERM

\section{Source}

INSERM. (1999). Orphanet: an online rare disease and orphan drug data base. $\underline{3-}$ methylg/utaconic aciduria type 4. ORPHA:67048

3-methylg lutaconic aciduria (3-MGA) type IV, or unclassified 3-MGA, is a clinically heterogeneous disorder characterised by increased 3-methylglutaconic acid excretion in individuals that cannot be classified as having one of the other forms of 3-MGA (3-MGA I, II or III). 